\title{
DEVELOPING A CARBON MANAGEMENT PLAN FOR THE ROYAL BOTANIC GARDEN EDINBURGH
}

\author{
Kate Hughes ${ }^{1}$, Kerstin Price ${ }^{2}$ \& Ian Lawrie ${ }^{3}$
}

\begin{abstract}
Royal Botanic Garden Edinburgh joined the Carbon Management-Lite Programme run by the Carbon Trust in November 2009. This paper provides details of the programme and the process of writing a Carbon Management Plan.
\end{abstract}

\section{INTRODUCTION}

At this most critical moment in human history, botanic gardens have the unique potential to be part of the solution to the interconnected challenges of biodiversity loss and climate change. They contribute directly to the generation of new scientific knowledge which enables us to understand, monitor and predict the changing world around us. They gather and protect the world's plant resources on which all other species depend. They build human capacity through formal and information educational programmes. Most importantly, they are places that can engage with people, informing and influencing them in ways that help to shape society. Unlike most research institutes botanic gardens are open to the public and some of them are significant visitor attractions." (Corporate Plan 2010/2011-2014/2015, Royal Botanic Garden Edinburgh, 2010a)

The Royal Botanic Garden Edinburgh's mission statement - 'exploring and explaining the world of plants for a better future' - commits us to working for a better future and our Corporate Plan 2010/11-2014/15 makes it clear that, in addition to the contributions we make through our research, conservation and education activities, we aspire to make every aspect of our operation more sustainable. (Carbon Management Plan, Royal Botanic Garden Edinburgh, 2010b)

In order to achieve an environmentally sustainable workplace the Senior Management Team (SMT) at RBGE has made a committment to achieving the international environmental standard ISO 14001. Participation in the Carbon Management-Lite Programme was partly motivated by a need for the organisation to be able to quantify its carbon

1. Kate Hughes is Sub-editor of Sibbaldia and Environmental Coordinator at Royal Botanic Garden Edinburgh (RBGE). Address: 20A Inverleith Row, Edinburgh, EH3 5LR. Email: K.Hughes@rbge.org.uk

2. Kerstin Price is Personal Assistant to the Director of Horticulture at RBGE. Email: K.Price@ rbge.org.uk

3. Ian Lawrie is Head of Estates Management at RBGE. Email: I.Lawrie@rbge.org.uk 
footprint, to allow for monitoring future emission reduction initiatives and to make use of the framework and tools that process provides in establishing a robust and clear carbon management system in line with the ISO standard.

The purpose of the RBGE Carbon Management Plan (CMP) (Royal Botanic Garden Edinburgh, 2010b) is to lay out the scope, issues, methods, people, paperwork and techniques necessary for RBGE to reduce its energy usage and therefore its carbon emissions. It does this by calculating the organisation's baseline of annual carbon emissions and then sets challenging targets to reduce these. The projects that will contribute to their reduction are listed and the way in which the Plan will be implemented is also described. The CMP also firmly ties in with the RBGE Corporate Plan 2010/11-2014/12, Environmental Policy (2004) and Sustainable Development Policy (2008), as well as our Environmental Management System to ensure a holistic and encompassing approach to reducing carbon emissions throughout the organisation's buildings, activities and sites including the three Regional Gardens at Dawyck, Logan and Benmore.

The development of the Plan started with an invitation from the Carbon Trust to join the Carbon Management-Lite Programme. The Carbon Trust is a not-for-profit company helping businesses and the public sector in Britain to cut their carbon emissions, reduce energy and support sustainable and low-energy technology.

The Carbon Management-Lite Programme is designed for small to medium sized organisations (SMEs) of 100-1,000 staff, with a low level of supervision from Carbon Trust staff. This is the 'Lite' element as this Programme has been delivered to larger organisations with greater input from Carbon Trust staff in the past. Many of the organisations that have been through the Programme are in the public sector and these include over 40 local authorities in Scotland, a high proportion of the colleges in Scotland and non-departmental public bodies (NDPBs) such as the National Galleries of Scotland, the National Library of Scotland and the National Museums of Scotland. As RBGE is comparable in size, extent of activities and funding to these organisations it was fitting that we went through the Programme at the same time as them.

The Project Leader, RBGE's Environmental Coordinator, attended an initial meeting in September 2009 which provided information on the scope and expectations of the Programme so that organisations could assess whether it would be suitable for their needs and whether they could provide the requirements for successful completion. This was a useful meeting and was followed by Workshop 1: The Kick Off Meeting of the Programme, in November 2009. This was attended by the Project Leader and other members of what became known as the Carbon Management Team (CMT).

WORKSHOP 1: THE KICK OFF MEETING - NOVEMBER 2009

All organisations taking part in the Programme alongside RBGE, which included Barony College, National Museums of Scotland, West Lothian College, National 
Galleries of Scotland, National Library of Scotland and Reid Kerr College, were invited to the workshop. The purpose of the workshop was to introduce us to the scope and timetable of the Programme and to address some of the initial issues that we could expect to encounter, such as key decisions that would be made and how we could expect the team to operate on a week-by-week basis.

Participants were also introduced to the 'Baseline Tool' (Carbon Trust, 2006), an MS Excel spreadsheet into which energy use figures are collated (see Fig. 1). The tool includes columns for:

- the areas of the site, usually defined by their association with a specific energy meter

- the type of accommodation - for example office space or housing

- the 'category' - this is either Edinburgh, Dawyck, Benmore or Logan

- the energy used in the area - this is provided by invoices and inputted by energy type, such as gas, oil or electricity

This tool transforms energy use into carbon emissions and financial costs using Department of Food and Rural Affairs (DEFRA) approved conversion factors (DEFRA, 2008) and summarises the information in graphs and pie charts. It also has a facility to input the reduction target and to calculate the carbon and cost savings that would be achieved if the target was reached. Two years later this tool has proved to be very useful in monitoring carbon emissions for the annual reporting cycle which is now a government requirement. It will also be useful for tracking the effectiveness of carbonsaving projects as they are put into place.

\begin{tabular}{|l|l|}
\hline Year & $\mathbf{2 0 1 0}$ \\
\hline No. of employees & 250 \\
\hline
\end{tabular}

\begin{tabular}{|c|c|c|c|c|c|c|c|}
\hline ID & Building or site & Energy User & Category (for graphs) & Amount & $\mathrm{CO}_{2}$ emission (kg) & $\operatorname{Cost}(\mathbf{f})$ & Type \\
\hline 1 & Edinburgh & Black stream - Domestic - Landfill & Black stream - Domestic & 34 & 15,198 & 1,122 & Waste \\
\hline 2 & Edinburgh - Dirty Works Clearances & Waste collected (tonnes) & Other & 7 & 3,263 & 7 & Waste \\
\hline 3 & Edinburgh & Red stream - Chemical waste - Recovery & Red stream-Chemical & - & - & - & Waste \\
\hline 4 & Benmore & Black stream - Domestic - Landfill & Black stream - Domestic & 7 & 3,129 & 231 & Waste \\
\hline 5 & Dawyck & Black stream - Domestic - Landfill & Black stream - Domestic & 4 & 1,788 & 132 & Waste \\
\hline \multirow[t]{3}{*}{6} & Logan & Black stream - Domestic - Landfill & Black stream - Domestic & 3 & 1,341 & 99 & Waste \\
\hline & Edinburgh - recycled & Black stream - Domestic - Recycling & Black stream - Domestic & & & & Waste \\
\hline & Logan - recycled & Black stream - Domestic - Recycling & Black stream - Domestic & & & & Waste \\
\hline \multirow[t]{2}{*}{5} & Edinburgh - Buchanan skip hire & Waste collected (tonnes) & Other & 13 & 5,874 & 13 & Waste \\
\hline & Edinburgh - ICT waste & Waste collected (tonnes) & Other & 0 & 176 & 0 & Waste \\
\hline & 010 Total & & & 69 & 30,769 & 1,605 & \\
\hline
\end{tabular}

Fig. 1 Screenshot of the 'Waste' tab of the Baseline Tool (Carbon Trust, 2006). Software provided by the Carbon Trust. 
One of the major outcomes of Workshop 1 was for RBGE to establish the Carbon Management Team (CMT) which would initially be responsible for the development of the CMP. The CMT consists of the following individuals:

- David Rae Director of Horticulture - Project Sponsor

- Kate Hughes Environmental Coordinator and Sub-editor of Sibbaldia-Project

\section{Leader}

- Ian Lawrie Head of Estates Management

- Jane Neville Head of Finance

- Ed Bain Head of ICT

- Kerstin Price PA to the Director of Horticulture

The members of the CMT were selected because the positions they held were key in ensuring the development and implementation of the Plan. The Senior Management Team at RBGE have made a committment to reducing its carbon impact, therefore it is expected that the roles and responsibilities outlined in this Plan would continue even if there was to be a change in personnel concerned.

\section{THE PROGRAMME}

The first workshop marked the start of the Programme and following the workshop participants were required to submit a Project Plan in which the major decisions, scope and responsibilities had been defined. The Project Plan included:

- what RBGE wanted to get out of the Programme

- who was to be involved with the project

- how the Programme would be managed

- which information would be measured and monitored through the Programme

This Project Plan ensured that the framework for our activities was set out and understood by all involved from the start and fortnightly CMT meetings were set up for the duration of the Programme. These regular meetings meant that there was regular tracking of progress and that any difficult issues were discussed and solutions explored at an early stage.

The Project Leader was also required to submit monthly reports to the support consultants. These reports provided details of progress, milestones reached and any problems encountered, for which advice was sometimes offered. This structured and proactive approach from the organisers of the Programme was very helpful in ensuring that we kept to the schedule because, as was made clear from the initial meeting, it was designed to be fast-paced and thorough. The timescale for the Programme is illustrated in Figure 2. There was one conference call between the support consultants and the CMT six weeks after the launch of the Programme and this enabled us to clarify some issues with the Baseline Tool spreadsheet and discuss any other problems that we encountered. 


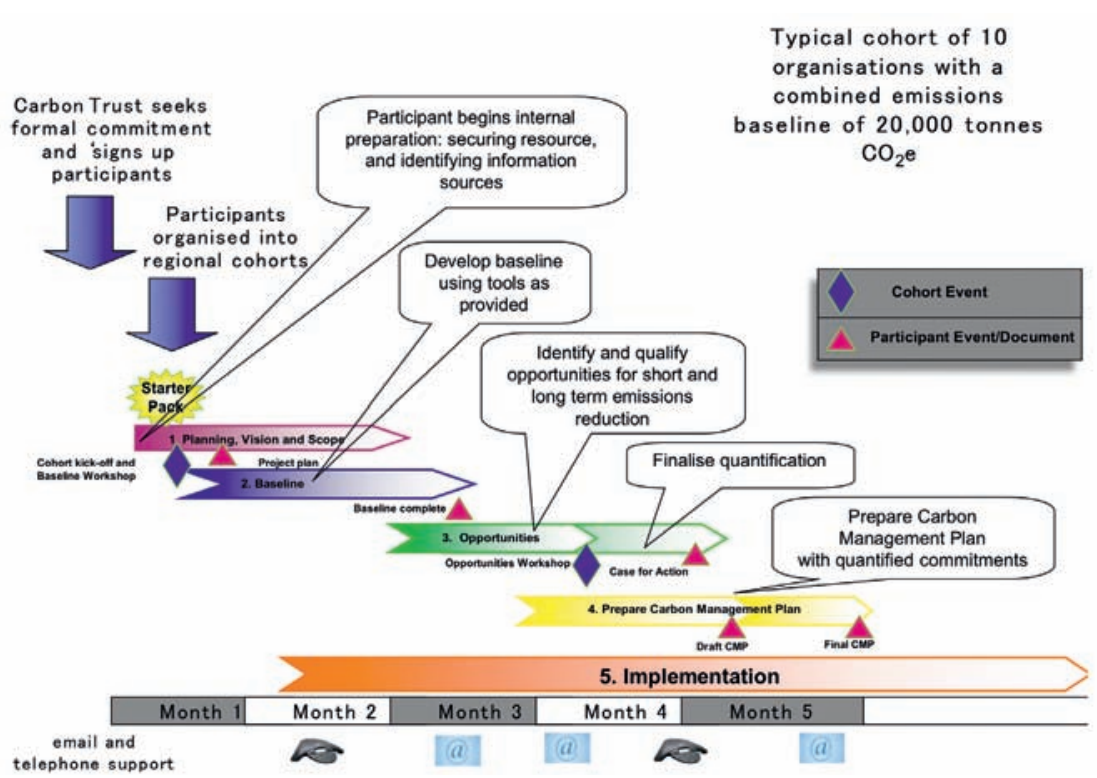

Fig. 2 Diagramatic representation of the Carbon Management Programme provided by the Carbon Trust. Diagram drawn by the Carbon Trust.

THE BASELINE TOOL

The Baseline Tool (Carbon Trust, 2006) is an MS Excel spreadsheet which manually logs the details of major emission sources such as buildings (the fuel used to heat and run them), transport (the type and distance travelled), waste (to landfill) and water used. The information is processed by the spreadsheet and converted into carbon emissions according to the amounts of fuel used. It is then put into summary graphs and tables showing the proportion of our emissions from these areas. This then enables us to see where our greatest emissions are and how to prioritise projects and resources to achieve the greatest reductions.

This initial data was extracted by the Project Leader and the PA to the Director of Horticulture, in many cases manually from the finance records. While all the information required is stored year on year at RBGE, at the beginning of the Programme it was not collected and stored in a way that was accessible for the purposes of the Programme. This led to a review by the CMT on how the data required could be collated and stored more efficiently, accurately and in a manner that would be easily accessible through the development of a Data Sourcing Map (see Fig. 3). Consequently, much of the data for running our extensive buildings and glasshouses, which accounts for the majority of our emissions, is now stored in an 'easy to get to' format by the Estates Management Department, making the annual update of the Baseline Tool a much simpler and more accurate task. 


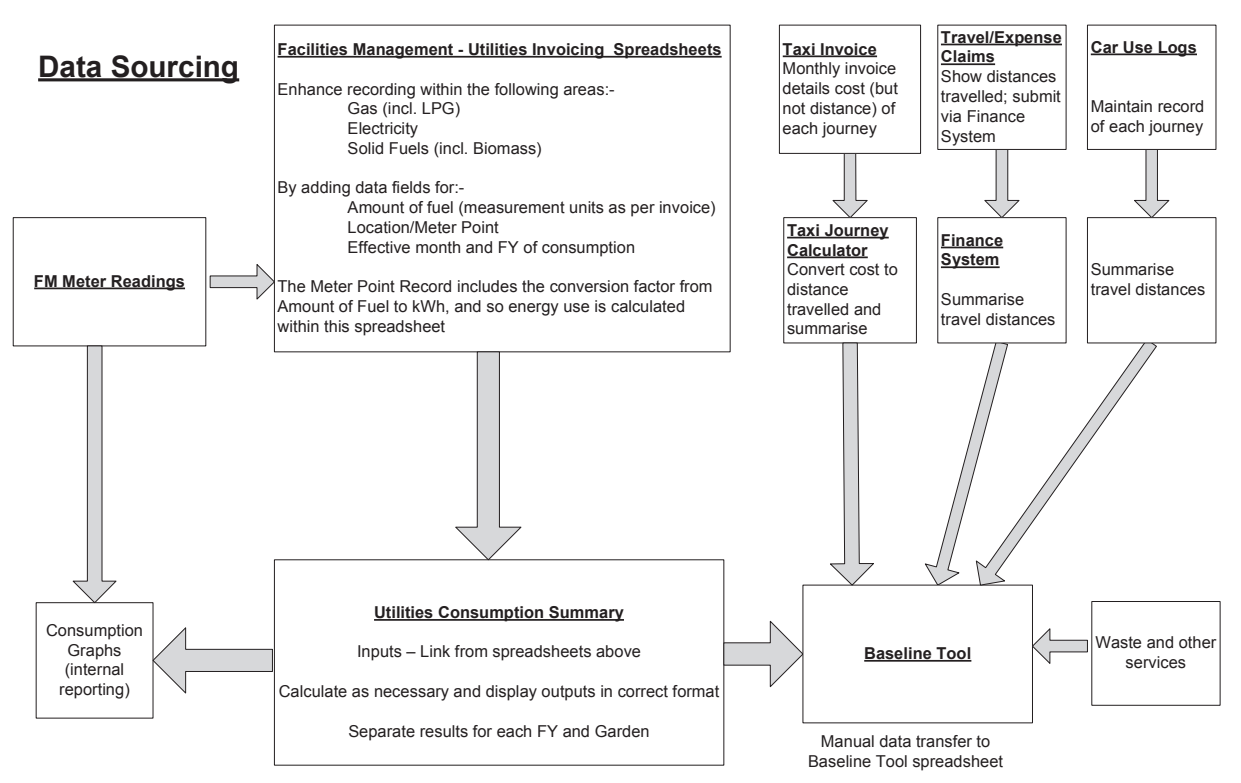

Fig. 3 Utilities Data Sourcing Map. Map drawn by Ed Bain.

The Estates Management Department already maintained spreadsheets of invoicing for goods and services supplied, including utilities. The utilities sheets were enhanced to also record the amount of the supply and, based on a conversion factor associated with each supplier and delivery point, to convert that amount as required for the Baseline Tool (for example from cubic metres of biomass fuel to $\mathrm{kWh}$ ). As there are multiple delivery points over multiple sites this data was also manipulated using a pivot table to provide summary data in the required format.

As invoice-based data is intrinsically historical in nature, meter readings are now also recorded, mainly manually at the moment. This allows more timely reporting on key metered delivery points. It is sometimes necessary to use such readings rather than delivery data to calculate consumption. Oil is purchased in large batches but may not be consumed until much later, for example to replace an interruptible gas supply in periods of high use.

The same issues of extracting data were encountered with our travel data which had been calculated by painstaking examination of travel agent documents and travel and subsistence claim forms to extract data on where staff had travelled to and by what method. This has been simplified since the start of the Programme with the inclusion of a column in the RBGE Credit Card Claim and Travel \& Subsistence Claim forms where staff now have to complete the number of miles travelled. Finance codes used to allocate expenses have also been amended to identify by what method staff have travelled. The Finance Department then import the data into their accounting system from which a 
simple report showing miles travelled can be created at the end of the year, thus making the process of collecting the data for the Baseline Tool much quicker and more accurate. The claims are returned unpaid by the Finance Department if this information is not completed.

The taxi company with which RBGE has an account was also contacted to ask if their monthly invoices could be sent electronically. This data is inserted into another spreadsheet which calculates the distance travelled by each journey based on the invoiced cost. This is then automatically summarised and fed into the Baseline Tool. As a part of this process the taxi bills were also examined and it was noticed that some journeys could have been made by bus. The Personal Assistants of all the Directors now hold bus tickets which staff can use when they need to make a local journey on business. Usage is not high and this practice does not make a major impact on our emissions but it is a representative action which we hope will encourage more sustainable travel and play a small part in reducing local traffic on our streets.

WORKSHOP 2: OPPORTUNITIES WORKSHOP - FEBRUARY 2010

In early February 2010 the second workshop bringing together all participants (see Fig. 4) of the Programme for the last time was held at the John Hope Gateway at RBGE (see Fig. 5). This brand new, sustainably constructed building was an ideal venue for the meeting. It operates with a number of energy-saving devices and renewable technologies

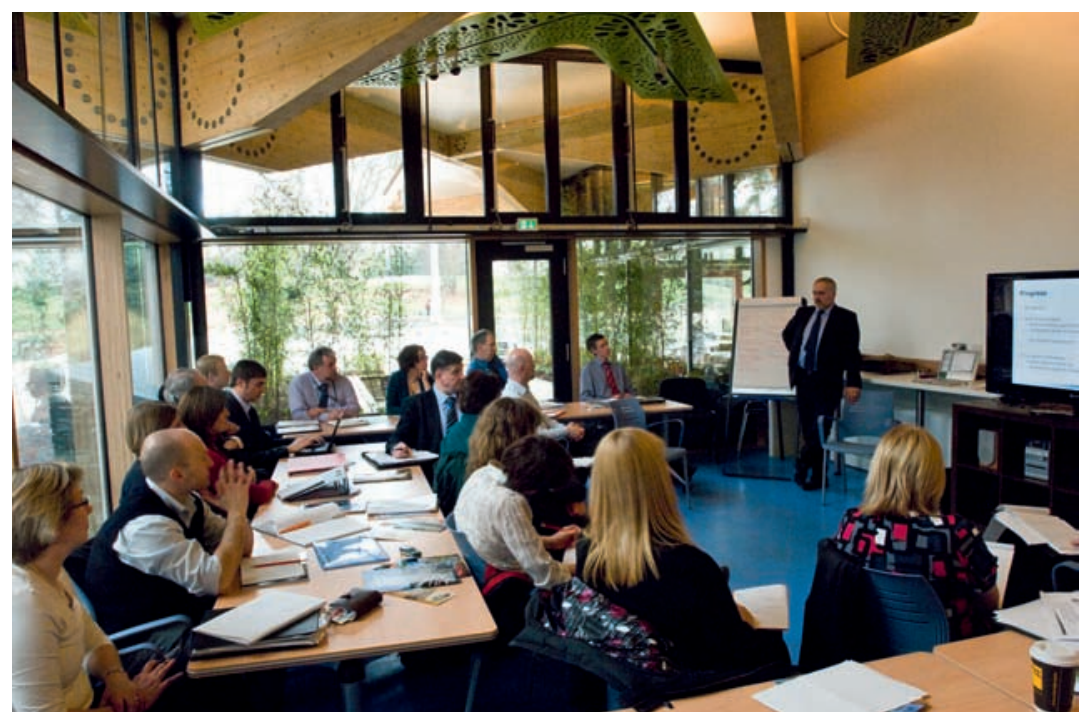

Fig. 4 Workshop 2 held in the Patrick Geddes Room, John Hope Gateway Visitor Centre. Photo: Lynsey Wilson. 


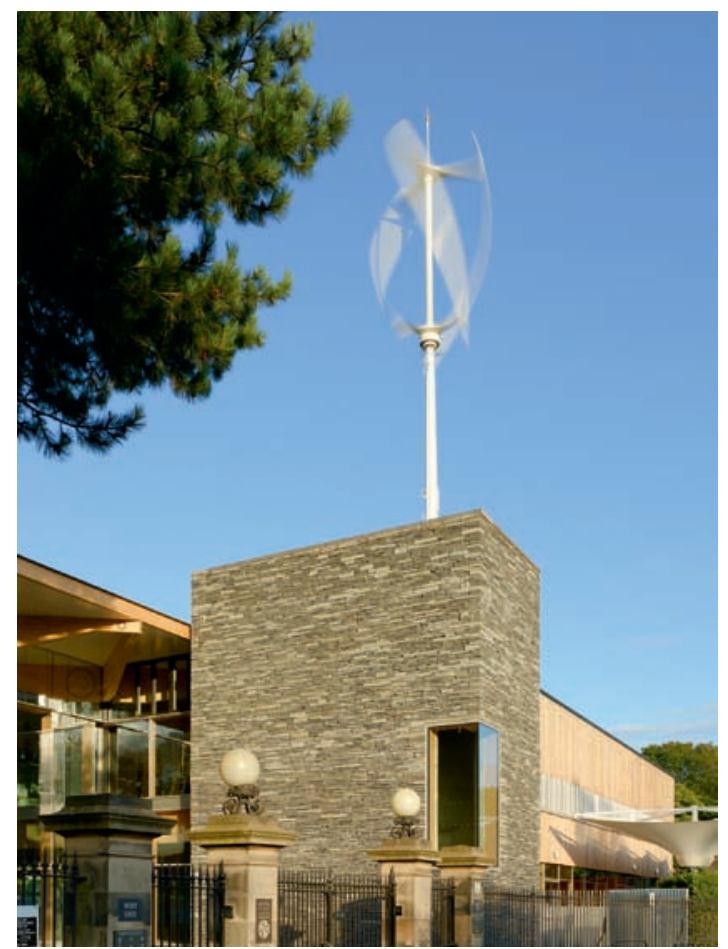

Fig. 5 The quietrevolution wind turbine at the John Hope Gateway Visitor Centre. Photo: Matt Laver, architectural photographer.

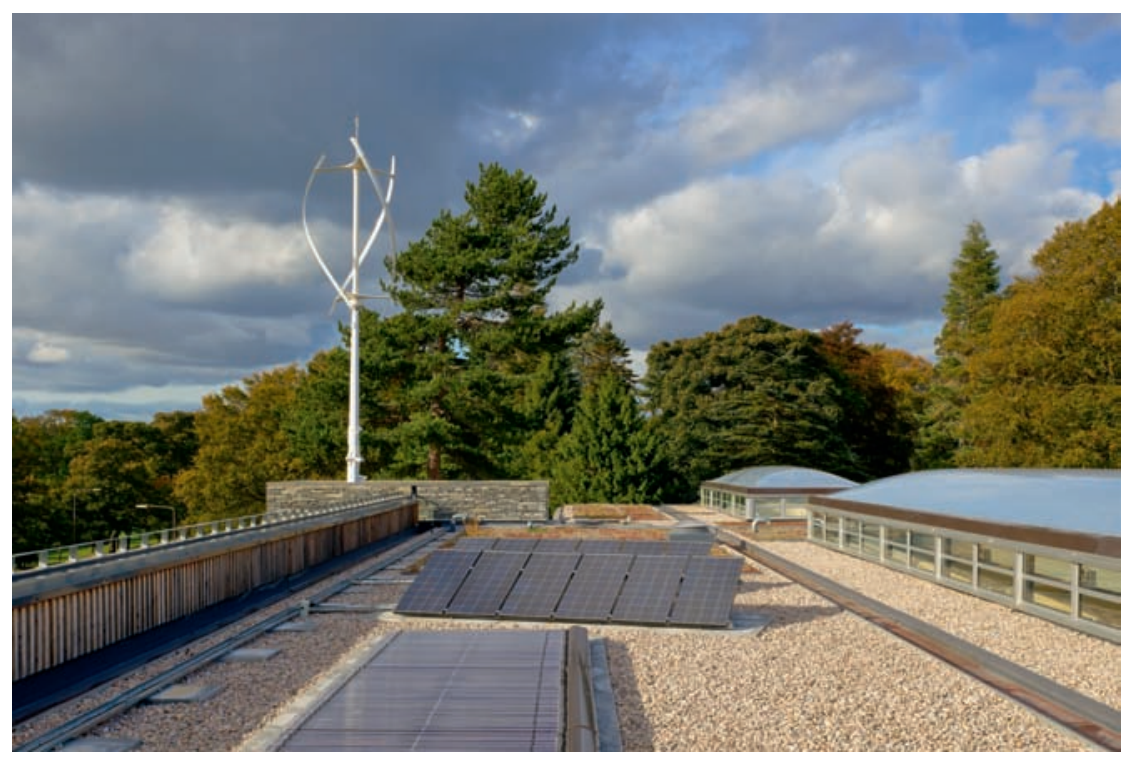

Fig. 6 Solar panels and heat exchangers installed on the roof of the John Hope Gateway Visitor Centre. The sedum roof and EFTE 'pillows' can also be seen. Photo: Matt Laver, architectural photographer. 
and the meeting concluded with a tour of these, including the biomass boiler, photovoltaic roof panels and solar water heating tubes, the quietrevolution wind turbine, sedum roof and rainwater collection systems (see Fig. 6).

At the workshop participants presented their baseline emissions and targets. Ideas for how to achieve these were shared and discussed but it was not expected that all projects that would help the organisations reach their set targets would have been identified and finalised by this point. This would happen in the final month of the programme, which was scheduled to finish at the end of April 2010.

\section{RBGE'S TARGET FOR CARBON EMISSIONS}

This organisation will reduce the $\mathrm{CO}_{2}$ emissions from its activities by $13 \%$ from the 2008 baseline by March 2015. If some key structures are rebuilt with a renewable energy source we will be able to further reduce these emissions by another $30 \%$.

This would make an overall reduction of $43 \%$ by March 2015. (CMP, page 9)

This opportunity to meet other participants as they went through the Programme was important because it put the issues, challenges and extent of our emissions into context. Nearly all those present believed that their organisation's carbon footprint was higher than necessary but that they had little power to reduce it because of a lack of funding, staff resources or information. The Programme was deemed to be fundamental in starting to find ways to solve these issues.

\section{THE CONTENTS OF THE PLAN}

In the CMP the sources of RBGE's carbon emissions are listed and it sets out the approach the organisation plans to take towards energy and carbon management.

The Plan also includes:

- a baseline of energy use calculated from 2008 against which the effect of action can be measured

- details on the conversion factors that have been used to determine the emissions figures

- the implications of various emission reduction scenarios including 'business as usual'

- targets for reduction in energy use and emissions

- key actions RBGE is taking to reduce carbon emissions

- a five-year programme of projects for carbon reduction (2010/11-2014/15)

- a programme for regular monitoring and review to assess and record progress

- finance and implementation for proposed projects

- an appendix which provides greater detail on the individual projects 
The Baseline Tool provides exact figures of what our emissions and costs will be if we do not try to reduce them. These are subject to the assumption that there will be a 0.7 per cent increase in demand for building resources and staff travel, and an 8.4 per cent increase in energy costs, although these are arguably a conservative estimate in the light of fuel price rises at the time of writing in March 2011. In April 2010 our costs were set to rise by over 50 per cent, from $£ 400,000$ to over $£ 800,000$, during the next nine years based on these conservative estimates. This rise in costs gives a compelling argument to reduce our energy use and emissions.

\section{CARBON MANAGEMENT PROJECTS}

Four categories of project were identified: existing projects, planned projects, near-term projects and medium- to long-term projects. These are illustrated in the tables in Figure 7. The existing, planned and near-term projects were developed to reach our aim of reducing our carbon emissions by at least 13 per cent by 2015. The implementation of the medium- to long-term projects would allow us to reduce our emissions by a further 30 per cent. These projects are subject to substantial funding and are therefore in their initial development phase.

In initiating these tables the CMT first discussed ideas for possible projects and changes to the existing infrastructure. With assistance from the Estates Management Department, the CMT members calculated the benefits and reductions that these projects would bring to current emissions through analysis of the data in the Baseline Tool and product specifications. In some cases these were estimates based on usage as inputted to the Tool and the capabilities of technology available. In this area support managers from the Carbon Trust were able to advise with their experience of the technology and equipment available and in particular they were able to provide estimated savings on the installation of most of the renewable technologies listed in the tables.

The tables illustrate that some technologies are predicted to bring worthwhile savings with relatively little capital cost, for example CR001 Server Virtualisation and CR011, the installation of a wind turbine at Logan Botanic Garden. Others, such as the installation of solar panels on the flat roof of the Herbarium (CR012), have a pay back of 25 years and are not viable projects at the time of writing. However, changes in technology, grant availability or other funding options may make this a viable project in the future and means that this project is still worth including in the Plan as one that the CMT would like to pursue when possible.

Based on the information put into the Baseline Tool the spreadsheet was then able to generate a graph (see Fig. 8) plotting the projected achievement towards the target.

\section{IMPLEMENTATION}

The final phase of writing the Plan involved agreeing with the CMT and SMT how it would be implemented. This included summarising the benefits - financial 
Existing projects

\begin{tabular}{|c|c|c|c|c|c|c|c|c|c|}
\hline \multirow{2}{*}{ Ref } & \multirow{2}{*}{ Project } & \multirow{2}{*}{ Lead } & \multicolumn{2}{|l|}{ Cost (E) } & \multicolumn{2}{|c|}{ Annual Saving } & \multirow{2}{*}{$\begin{array}{l}\text { Pay } \\
\text { back }\end{array}$} & \multirow{2}{*}{$\begin{array}{l}\% \text { of } 13 \% \\
\text { Target }\end{array}$} & \multirow{2}{*}{ Year } \\
\hline & & & Capital & Revenue & Financial & $\mathrm{CO}_{2}$ & & & \\
\hline $\begin{array}{l}\text { RBGE } \\
\text { CR001 }\end{array}$ & $\begin{array}{l}\text { Server } \\
\text { Virtualisation }\end{array}$ & ICT & ESK & fo & E7.2K & $46 t$ & 9mths & $8.3 \%$ & 2009 \\
\hline $\begin{array}{l}\text { RBGE } \\
\text { CRO02 }\end{array}$ & Thin Clients & ICT & fo & fo & $\begin{array}{l}\text { f90(ph1) } \\
+\varepsilon 104(\mathrm{ph} 2)\end{array}$ & $1.2 \mathrm{t}$ & $n / a$ & $0.2 \%$ & 2009 \\
\hline $\begin{array}{l}\text { RBGE } \\
\text { CRO03 }\end{array}$ & $\begin{array}{l}\text { Install Heat } \\
\text { Curtains }\end{array}$ & FM & fo & f7K & Dte' & $6.6 \mathrm{t}$ & 7.2 yrs & $1.1 \%$ & 2009 \\
\hline $\begin{array}{l}\text { RBGE } \\
\text { CROO4 }\end{array}$ & $\begin{array}{l}\text { Lighting } \\
\text { survey }\end{array}$ & FM & fo & $f 3,243$ & $\operatorname{Dte}^{1}$ & $\begin{array}{l}564 k \\
g\end{array}$ & & $0.1 \%$ & 2010 \\
\hline $\begin{array}{l}\text { RBGE } \\
\text { CR008 }\end{array}$ & $\begin{array}{l}\text { Insulation for } \\
\text { buildings }\end{array}$ & FM & fo & f10K & Dte' & Dte' & & & 2010 \\
\hline
\end{tabular}

Planned/funded projects

\begin{tabular}{|c|c|c|c|c|c|c|c|c|c|}
\hline \multirow{2}{*}{ Ref } & \multirow{2}{*}{ Project } & \multirow{2}{*}{ Lead } & \multicolumn{2}{|l|}{ Cost (E) } & \multicolumn{2}{|c|}{ Annual Saving } & \multirow{2}{*}{$\begin{array}{l}\text { Pay } \\
\text { back }\end{array}$} & \multirow{2}{*}{$\begin{array}{l}\% \text { of } 13 \% \\
\text { Target }\end{array}$} & \multirow{2}{*}{ Year } \\
\hline & & & Capital & Revenue & Financial & $\mathrm{CO}_{2}$ & & & \\
\hline $\begin{array}{l}\text { RBGE } \\
\text { CR011 }\end{array}$ & $\begin{array}{l}\text { Logan - } \\
\text { Wind Turbine }\end{array}$ & FM & f45.9K & fo & f5.6k & $38.8 \mathrm{t}$ & 9.9 & $7 \%$ & $\begin{array}{l}2012- \\
13\end{array}$ \\
\hline $\begin{array}{l}\text { RBGE } \\
\text { CR013 }\end{array}$ & $\begin{array}{l}\text { Dawyck- } \\
\text { Hydro }\end{array}$ & FM & ESOK & fo & f7.0k & $48 \mathrm{t}$ & 3 years & $8.6 \%$ & $\begin{array}{l}2012- \\
13\end{array}$ \\
\hline $\begin{array}{l}\text { RBGE } \\
\text { CR007 }\end{array}$ & $\begin{array}{l}\text { Reglazing } \\
\text { Herbarium }\end{array}$ & FM & f150-200K & fo & f190K & $14.3 \mathrm{t}$ & 2 years & $2.5 \%$ & $\begin{array}{l}2014- \\
15\end{array}$ \\
\hline $\begin{array}{l}\text { RBGE } \\
\text { CR009 }\end{array}$ & $\begin{array}{l}\text { Benmore - } \\
\text { Biomass }\end{array}$ & FM & f11.1K & fo & f3.4K & $16.1 t$ & $\begin{array}{l}3.27 \\
\text { years }\end{array}$ & $2.9 \%$ & $\begin{array}{l}2011- \\
12\end{array}$ \\
\hline $\begin{array}{l}\text { RBGE } \\
\text { CR010 }\end{array}$ & $\begin{array}{l}\text { Logan. } \\
\text { Biomass }\end{array}$ & FM & E9.9K & fo & f2.2K & $10.7 t$ & $\begin{array}{l}4.39 \\
\text { years }\end{array}$ & $1.93 \%$ & $\begin{array}{l}2011- \\
12\end{array}$ \\
\hline
\end{tabular}

Near-term projects

\begin{tabular}{|c|c|c|c|c|c|c|c|c|c|}
\hline \multirow{2}{*}{ Ref } & \multirow{2}{*}{ Project } & \multirow{2}{*}{ Lead } & \multicolumn{2}{|l|}{ Cost (f) } & \multicolumn{2}{|c|}{ Annual Saving } & \multirow{2}{*}{$\begin{array}{l}\text { Pay } \\
\text { back }\end{array}$} & \multirow{2}{*}{$\begin{array}{l}\% \text { of } \\
13 \% \\
\text { Target }\end{array}$} & \multirow{2}{*}{ Year } \\
\hline & & & Capital & Revenue & Financial & $\mathrm{CO}_{2}$ & & & \\
\hline $\begin{array}{l}\text { RBGE } \\
\text { CROoS }\end{array}$ & $\begin{array}{l}\text { Food Waste } \\
\text { Segregation } \\
\text { and Invessel } \\
\text { Composter }\end{array}$ & $\begin{array}{l}\text { Waste } \\
\text { EMG \& } \\
\text { Hort } \\
\text { Dept }\end{array}$ & f15K & fo & & $5.8 \mathrm{t}$ & & $1.05 \%$ & $\begin{array}{l}2013- \\
14\end{array}$ \\
\hline $\begin{array}{l}\text { RBGE } \\
\text { CRO06 }\end{array}$ & $\begin{array}{l}\text { Reduction in } \\
\text { Staff Travel }\end{array}$ & $\begin{array}{l}\text { Travel } \\
\text { Group } \\
\text { EMG }\end{array}$ & Dte' & fo & Dte' & $28 \mathrm{t}$ & Dte' & $5.7 \%$ & 2011 \\
\hline $\begin{array}{l}\text { RBGE } \\
\text { CR012 }\end{array}$ & $\begin{array}{l}\text { Herb Roof - } \\
\text { Solar Panels }\end{array}$ & FM & f $488 \mathrm{~K}$ & fo & f19.8Kpa & 38.1t & $\begin{array}{l}25 \\
\text { years }\end{array}$ & $6.9 \%$ & $\begin{array}{l}2012- \\
13\end{array}$ \\
\hline
\end{tabular}

Medium- to long-term projects

\begin{tabular}{|c|c|c|c|c|c|c|c|c|c|}
\hline \multirow{2}{*}{ Ref } & \multirow{2}{*}{ Project } & \multirow{2}{*}{ Lead } & \multicolumn{2}{|l|}{ Cost (E) } & \multicolumn{2}{|c|}{ Annual Saving } & \multirow{2}{*}{$\begin{array}{l}\text { Pay } \\
\text { back }\end{array}$} & \multirow{2}{*}{$\begin{array}{l}\% \text { of } 43 \% \\
\text { Target }\end{array}$} & \multirow{2}{*}{ Year } \\
\hline & & & Capital & Revenue & Financial & $\mathrm{CO}_{2}$ & & & \\
\hline $\begin{array}{l}\text { RBGE } \\
\text { CR015 }\end{array}$ & $\begin{array}{l}\text { N E Corner } \\
\text { Development }\end{array}$ & FM & E30M & & $89 \mathrm{~K}$ & $661 t$ & $\begin{array}{l}337 \\
\text { years }\end{array}$ & $72 \%$ & 2015 \\
\hline $\begin{array}{l}\text { RBGE } \\
\text { CR005 }\end{array}$ & $\begin{array}{l}\text { Change } \\
\text { Electricity } \\
\text { Supplier }\end{array}$ & FM & & & & & & & \\
\hline
\end{tabular}

'Dte-Difficult to estimate. The savings on these projects are difficult to estimate due to the size of the metered area or nature of the changes such as the costs of electricity or train fares. Savings or possible increases in costs will be visible in fuel and other invoices in the future.

Fig. 7 Tables of projects reproduced from the CMP (Royal Botanic Garden Edinburgh, 2010). 


\section{CO2 Savings}

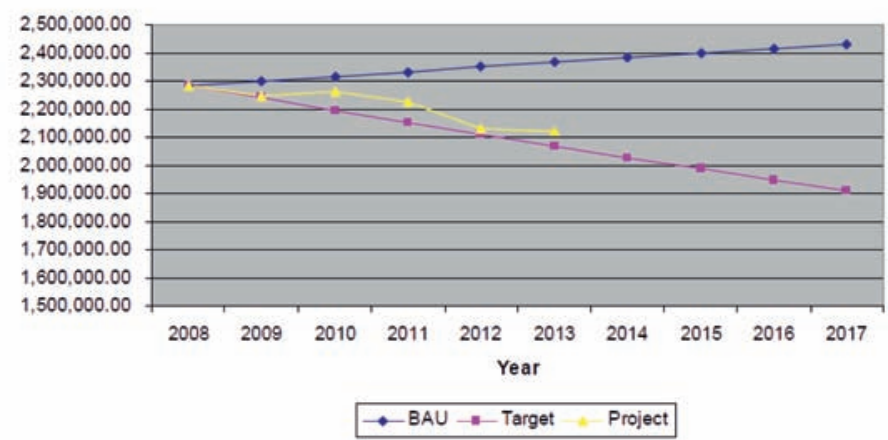

Fig. 8 Projected Achievement Towards Target: Chart showing RBGE BaU emissions, the 13 per cent target and the cumulative progression towards the target levels. Reproduced from the CMP (Royal Botanic Garden Edinburgh, 2010).

and unquantifiable - and costs if all elements of the Plan were in place. All of the costed projects rely on capital funding and therefore they are all dependent on the total capital budget allocated to RBGE by the Rural and Environment Science and Analytical Services Division (RESAS), our funding body. However, there are other benefits to putting mechanisms in place to measure, monitor and reduce our emissions and these are:

- contribution to achieving standards comparable with the environmental standard ISO 14001

- facilitating a change in work culture to one of increasingly considering the resources required to carry out our work and reducing wastage of these

- an increase in opportunities to communicate with the public and other users of our facilities about our activities. This leads to educational opportunities and raising the profile of these issues society-wide.

These can be summed up by the progression of behavioural and psychological changes which acknowledge that we must all do what we can to reduce wastage of resources at all levels while carrying out our work.

The Plan may develop and change over time because of changes in policy, funding or technology. This is why the medium- to long-term projects are listed as projects that we would like to pursue in the future and which would reduce emissions considerably. However, the extent of funding and infrastructure required make these projects difficult to quantify or implement in the current funding climate.

The SMT have approved and adopted the CMP and have asked for an annual update on progress made (see Fig. 9). They have further requested that any specific issues or problems be tabled when they arise. The Director of Horticulture, who is also the Project 
Sponsor, keeps the other Directors informed on progress at regular Senior Management Team meetings. Trustees have also been kept informed of progress and receive reports through the Director of Horticulture.

Ownership of implementation lies with the CMT but progress and scrutiny are the responsibility of the SMT. The Plan and future developments contained within it will be affected and informed by the annual Targets and Objectives Workshop which is part of the Environmental Management System (EMS). The CMP was approved in June 2010 and the CMT has moved on to the implementation phase. The CMT will continue to meet on a monthly basis to discuss progress made, review the CMP, populate the Baseline Tool, develop new capital projects and apply to Trusts and Funds for financial help.

\section{PUTTING THE PLAN INTO ACTION}

The implementation of existing projects is ongoing and a commitment to dedicate 10 per cent of RBGE's annual Capital Budget for a period of five years has been agreed by the SMT. This is always dependent on the approval of the overall budget by RBGE's funding body, RESAS. The first projects to be successful in being allocated capital funding in the Planned/Funded Projects table are the wind turbine at Logan Botanic Garden and the installation of hydro power at Dawyck Botanic Garden. The Carbon Trust has also agreed to fund feasibility studies into the installation of biomass boilers at two of our Regional Gardens, Benmore and Logan.

At the time of writing these projects are being progressed and we hope to be able to measure their benefits in the financial year which ends in March 2013.

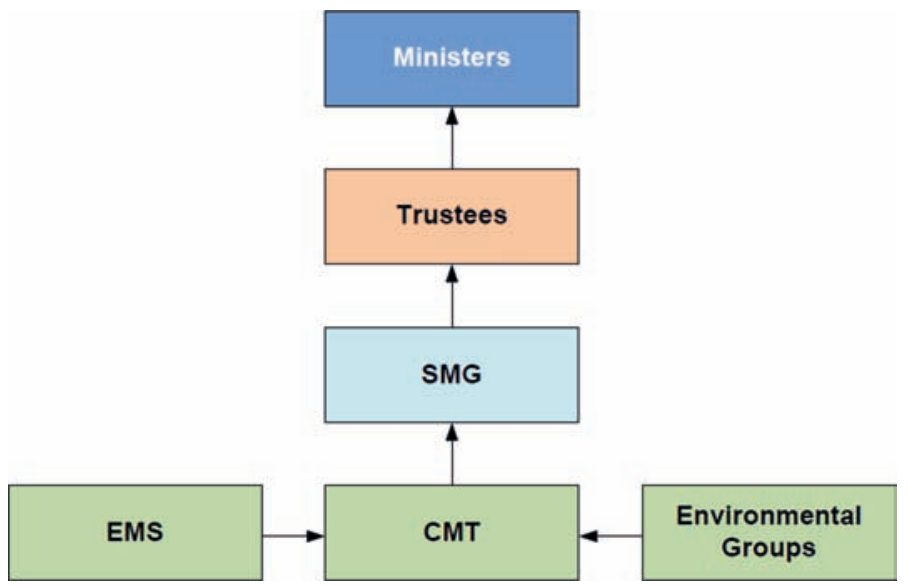

Fig. 9 CMP Implementation Management Structure. Reproduced from the CMP (Royal Botanic Garden Edinburgh, 2010). 


\section{Our Low Carbon Vision}

RBGE will endeavour to continually reduce its energy use by streamlining our activities and including all staff in these efforts. We aim to work together with staff towards reducing our carbon footprint by at least $13 \%$ by 2015 . This could be increased to $43 \%$ if key structures and heating systems were replaced. (CMP, page 8)

\section{ACKNOWLEDGEMENTS}

The authors would like to thank Ed Bain for his comments and for providing the Data Sourcing Map (see Fig. 3).

\section{REFERENCES}

CARBON TRUST (2006). Baseline Tool. [Microsoft Excel] Carbon Trust.

DEFRA (2008). Guidelines to DEFRA's GHG conversion factors. Available at: http://archive. defra.gov.uk/environment/business/reporting/pdf/ghg-cf-guidelines-annexes2008.pdf (accessed November 2009).

ROYAL BOTANIC GARDEN EDINBURGH (2010a). Corporate Plan 2010/2011-2014/2015. Unpublished. Royal Botanic Garden Edinburgh.

ROYAL BOTANIC GARDEN EDINBURGH (2010b). Carbon Management Plan. Unpublished. Royal Botanic Garden Edinburgh. 